\title{
Congenital fistula from the left main coronary artery to the left atrium presenting with an acute myocardial infarction
}

\author{
Melissa M. Anastacio, MD, Anson M. Lee, MD, and Jennifer S. Lawton, MD, St Louis, Mo
}

Congenital coronary artery fistula $(\mathrm{CAF})$ is a rare anomaly, diagnosed in approximately $0.2 \%$ of all patients undergoing cardiac catheterization. ${ }^{1}$ We present a unique case of a CAF between the left main coronary artery (LMCA) and the left atrium in a man who sought treatment for an acute myocardial infarction.

\section{CLINICAL SUMMARY}

A 23-year-old man with a history of Asperger syndrome had been born with LMCA to left atrial fistula and had undergone 2 coil embolizations at the ages of 5 and 7 years. At the age of 17 years, he had a myocardial infarction, which was attributed to embolism to a marginal branch of the left circumflex coronary artery. Cardiac catheterization at the time showed residual flow through the portion of the CAF between the left main ostium and the coils. The patient returned in March 2012 with chest pain and was found to have a myocardial infarction. Computed tomographic scan demonstrated persistence of the fistula to the coils, as well as thrombus within the fistula and all 3 branches of the LMCA (Figure 1). After transfer to our institution, the patient had recurrent chest pain with electrocardiographic changes. Urgent cardiac catheterization demonstrated a fistula originating within millimeters of the left main ostium and the previously placed coils (Figure 2, A and $B$ ). Proximal thrombus was identified in the left anterior descending coronary artery, the ramus, and the left circumflex coronary artery.

The patient was urgently taken to the operating room. Under cardioplegic arrest, the LMCA was extremely friable and tore easily, even with gentle dissection. The LMCA just before its branching and the inferior path of the fistula were therefore both ligated. The previously placed coils were visualized superiorly near Waterston's groove. A bovine pericardial patch was sewn inside the aorta, where the left main ostium had been and only friable tissue remained. Coronary artery bypass grafting was performed with the left

\footnotetext{
From the Division of Cardiothoracic Surgery, Department of Surgery, Washington University School of Medicine in St Louis, St Louis, Mo.

Disclosures: Authors have nothing to disclose with regard to commercial support. Received for publication May 30, 2012; revisions received Aug 13, 2012; accepted for publication Sept 12, 2012; available ahead of print Oct 5, 2012.

Address for reprints: Jennifer S. Lawton, MD, Washington University School of Medicine, 660 S Euclid Ave, Campus Box 8234, St Louis, MO 63110 (E-mail: lawtonj@wustl.edu).

J Thorac Cardiovasc Surg 2012;144:e147-8

$0022-5223 / \$ 36.00$

Copyright (c) 2012 by The American Association for Thoracic Surgery

http://dx.doi.org/10.1016/j.jtcvs.2012.09.015
}

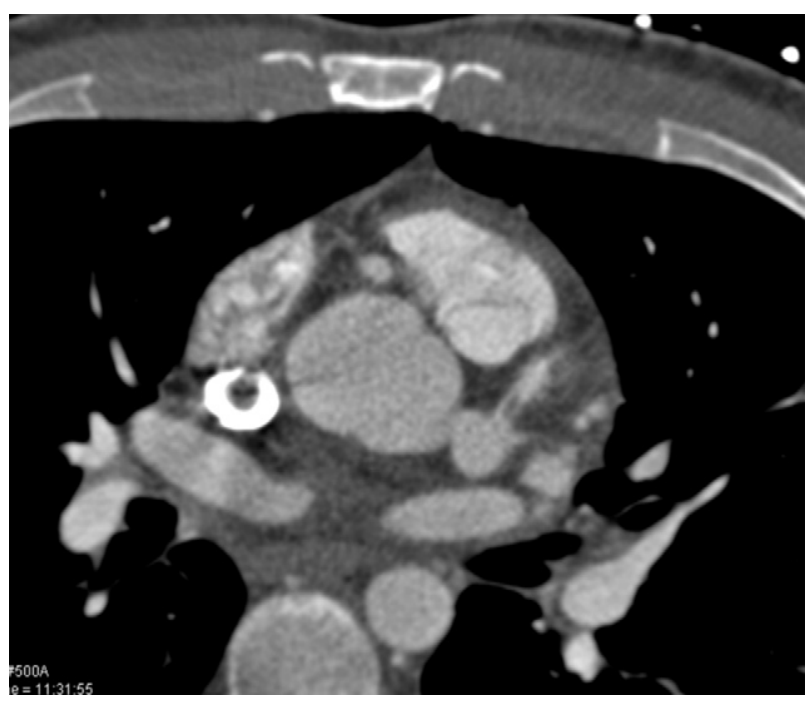

FIGURE 1. A representative slice of the chest computed tomographic scan shows an aneurysmal left main coronary artery and thrombus in the proximal left anterior descending coronary artery.

internal thoracic artery to the left anterior descending coronary artery and the left radial artery to the ramus and sequenced to the distal obtuse marginal artery. The patient was discharged on postoperative day 4 and was doing well at 6 weeks of follow-up.

\section{DISCUSSION}

Although it is rare, CAF represents the most common congenital coronary anomaly. ${ }^{2}$ CAF can be single or multiple, and it may be associated with other cardiac abnormalities. ${ }^{1,2}$ CAFs predominantly arise from the right coronary artery and empty into the right side of the heart or great vessels. Left-sided CAF with drainage into the left side of the heart is an especially rare entity, accounting for $2 \%$ to $6 \%$ of all CAFs. ${ }^{1,2}$

A continuous murmur is often found on physical examination. CAFs are usually asymptomatic. ${ }^{1}$ When symptoms are present, they are typically associated with congestive heart failure, reflecting the predominance of right-sided $\mathrm{CAF}^{1,2}$ Less frequently, CAFs may cause angina, atrial fibrillation, endocarditis, and aneurysmal dilation. Spontaneous closure has been reported in $1 \%$ to $23 \%$ of cases. ${ }^{1,3}$

Cardiac catheterization is the criterion standard diagnostic test. It can identify the fistula, clearly define the coronary artery anatomy and the involved cardiac chamber or great vessel, and measure the hemodynamic significance of the fistula. 


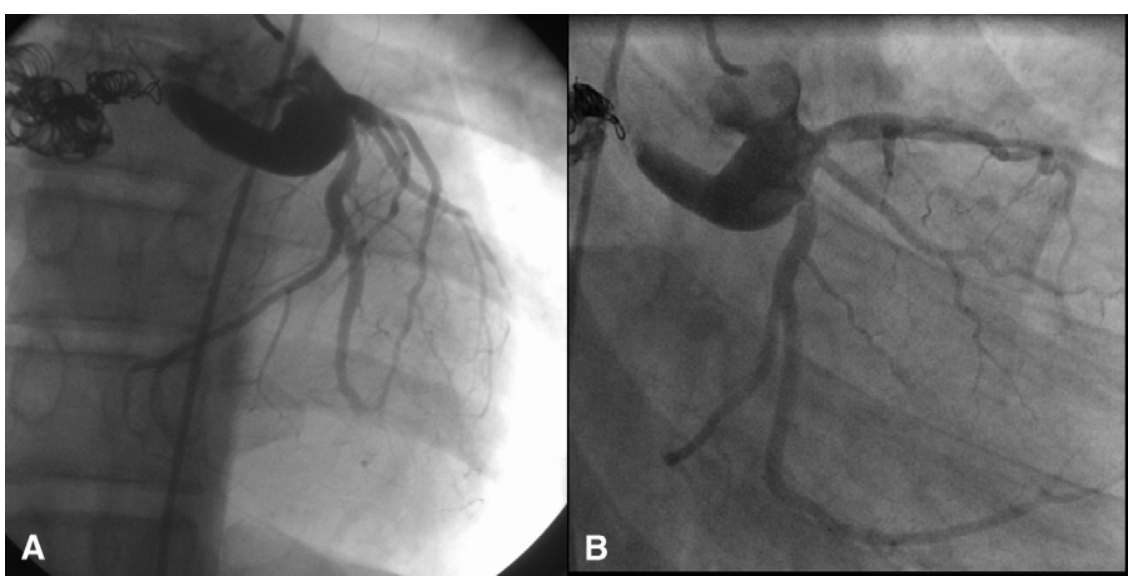

FIGURE 2. A, Cardiac catheterization shows the previously placed coils and the aneurysmal left main coronary artery. B, Also visible are filling defects in all proximal 3 branches of the left main coronary artery, which represent thrombus.

All large or symptomatic CAFs should be closed either operatively or percutaneously. ${ }^{4}$ Small, asymptomatic CAFs can be monitored with serial echocardiograms every 3 to 5 years. ${ }^{4}$

Closure has classically involved ligation of the CAF, with or without cardiopulmonary bypass, with low morbidity and mortality. ${ }^{1,2}$ For larger, more complex CAFs, fistula takedown may involve primary repair, pledgeted closure, or coronary artery bypass grafting. Alternatively, transcatheter closure can be used in select cases of CAF. ${ }^{5}$ Although no standardized selection criteria exist; clinically significant CAF, multiple CAFs, CAFs in close proximity to other major coronary arteries, and associated complex heart disease requiring surgery may prohibit transcatheter closure.

\section{CONCLUSIONS}

We report the successful treatment of a man with a left main CAF. CAFs are rare congenital coronary anomalies.
Although predominantly asymptomatic, they can result in significant sequelae, including myocardial infarction. Surgical repair continues to be the criterion standard in the management of CAF, although percutaneous technology has evolved into a viable alternative in select cases.

\section{References}

1. Cheung DLC, Au WK, Cheung HH, Chiu CS, Lee WT. Coronary artery fistulas: long-term results of surgical correction. Ann Thorac Surg. 2001;71:190-5.

2. Lowe JE, Oldham HN Jr, Sabiston DC Jr. Surgical management of congenital coronary artery fistulas. Ann Surg. 1981;194:373-80.

3. Sherwood MG, Rockenmacher S, Colan SD, Geva T. Prognostic significance of clinically silent coronary artery fistulas. Am J Cardiol. 1999;83:407-11.

4. Warnes CA, Williams RG, Bashore TM, Child JS, Connolly HM, Dearani JA, et al. ACC/AHA 2008 Guidelines for the Management of Adults with Congenital Heart Disease: a report of the American College of Cardiology/American Heart Association Task Force on Practice Guidelines (writing committee to develop guidelines on the management of adults with congenital heart disease). Circulation. 2008;118:e714-833.

5. Valente AM, Lock JE, Gauvreau K, Rodriguez-Huertas E, Joyce C, Armsby L, et al. Predictors of long term adverse outcomes in patients with congenital coronary artery fistulae. Circ Cardiovasc Interv. 2010;3:134-9.

\title{
Video-assisted thoracoscopic surgical lobectomy with limited en bloc resection of superior sulcus tumor
}

\author{
Ivan H. W. Cheung, MBBS, BEng, ${ }^{\text {a } a n d ~ E r i c ~ L i m, ~ M D, ~ M B, ~ C h B, ~ M S c, ~ F R C S(C-T h), ~}{ }^{\text {a,b }}$ London, \\ United Kingdom
}

\footnotetext{
From the Imperial College School of Medicine, ${ }^{a}$ London, United Kingdom; and the Academic Division of Thoracic Surgery, ${ }^{\mathrm{b}}$ Royal Brompton Hospital, London, United Kingdom.

Disclosures: Authors have nothing to disclose with regard to commercial support.

Received for publication July 10, 2012; revisions received Aug 19, 2012; accepted for publication Sept 12, 2012; available ahead of print Oct 5, 2012.

Address for reprints: Eric Lim, MD, MB, ChB, MSc, FRCS(C-Th), Imperial College and The Academic Division of Thoracic Surgery, Royal Brompton Hospital, Sydney St, London SW3 6NP, UK (E-mail: e.lim@rbht.nhs.uk).

J Thorac Cardiovasc Surg 2012;144:e148-51

0022-5223/\$36.00

Copyright (C) 2012 by The American Association for Thoracic Surgery

http://dx.doi.org/10.1016/j.jtcvs.2012.09.017
}

A superior sulcus tumor arises from the recess of the pulmonary superior sulci and often extends beyond the lung to invade the structures within the thoracic inlet. Pearson and colleagues ${ }^{1}$ defined a superior sulcus tumor as any apical tumor with associated pain around the shoulder and extending down into the arm. This type of non-small cell carcinoma represents fewer than $5 \%$ of all lung cancers and can be subdivided according to the anatomic position at the apex: the posteriorly located tumors (such as the classic Pancoast 